\title{
ELEIÇÃO PRESIDENCIAL DA RÚSSIA EM 2018: DEBATES PRESIDENCIAIS E A AUDI- ÊNCIA NO YOUTUBE
}

THIAGO PEREZ BERNARDES DE MORAES CENTRO UNIVERSITÁRIO CAMPOS DE ANDRADE

CURITIBA, PARANÁ, BRASIL THIAGOMORAESSP@HOTMAIL.COM 


\section{ELEIÇÃO PRESIDENCIAL DA RÚSSIA EM 2018: DEBATES PRESIDEN- CIAIS E A AUDIÊNCIA NO YOUTUBE}

Resumo: Este trabalho traz cinco hipóteses sobre a eleição presidencial russa de (2018) e o padrão de uso do Youtube: a) Putin provavelmente foi o candidato mais popular; (b) possivelmente os debates afetaram o interesse por candidatos; (c) possivelmente os debates pressões distintas no interesse por candidatos; (d) o último debate (próximo ao dia D) possivelmente foi o que mais gerou acessos; (e) possivelmente, as buscas no Youtube afetaram pouco as intenções de voto. Os resultados corroboram as hipóteses e apontam para um ciberespaço político russo que age como contrapeso à falta de espaço dos candidatos nos meios de comunicação de massa.

Palavras Chave: Rússia, eleições presidenciais, 2018, Youtube.

\section{ELECCIONES PRESIDENCIALES DE RUSIA, 2018: DEBATES PRESI- DENCIALES Y LA AUDIENCIA DE YOUTUBE}

Resumen: Este artículo presenta cinco hipótesis sobre la elección presidencial rusa de (2018) y el uso de Youtube: a) Putin fue probablemente el candidato más popular; (b) posiblemente los debates afectaron el interés en los candidatos; (c) posiblemente los debates hayan afectado claramente el interés en los candidatos; (d) el último debate (cercano al día $D$ ) fue posiblemente el que generó la mayor cantidad de visitas; (e) posiblemente, las búsquedas en YouTube tuvieron poco efecto en las intenciones de voto. Los resultados corroboran las hipótesis y apuntan a un ciberespacio político ruso que actúa como contrapeso a la falta de espacio de los candidatos en los medios de comunicación.

Palabras Clave: Rusia, elecciones presidenciales, 2018, YouTube.

\section{RUSSIAN PRESIDENTIAL ELECTION 2018: PRESIDENTIAL DEBATES}

\section{AND THE YOUTUBE AUDIENCE}

Abstract: This paper presents five hypotheses regarding the Russian presidential election of (2018) and the use of Youtube: a) Putin was probably the most popular candidate; (b) possibly the debates affected the interest in candidates; (c) possibly the debates have distinctly affected interest in candidates; (d) the last debate (close to D-day) was possibly the one that generated the most hits; (e) possibly, searches on YouTube had little effect on voting intentions. The results corroborate the hypothesis and point to a Russian political cyberspace that acts as a counterweight to the candidates' lack of space in the mass media.

Keywords: Russia, presidential elections, 2018, Youtube. 


\section{INTRODUÇÃO}

O advento das mídias sociais trouxe uma nova dinâmica quanto à temporalidade da cultura e da imagem das "figuras públicas". Os recursos participativos permitem que muitos aspirantes comuns consigam a dianteira na condução de práticas de autopromoção de imagem, mantendo assim um público de usuários pares, compondo bases de fãs, algo como uma extensão do status, e que às vezes ultrapassa os limites esperáveis da indústria e da mídia de entretenimento. Nesse ponto, a rede social que mais tem se destacado pelo potencial de influência social e política tem sido o Youtube (LOBATO, 2016; WEIJ; BERKERS, 2017; HOU, 2018). É evidente que a disseminação de informação e de mecanismos democráticos de discussão também pode ser interpretada nesse ponto como uma contribuição para a democratização do discurso público e das pautas políticas.

Na mesma esteira no que tange ao ciberespaço russo, Karina Alexanyan e seus colaboradores (2014) afirmam que este tem se tornado um nicho cada vez mais disputado, pois os atores naturalmente procuram moldar o ambiente digital, embora o foco da influência e do controle sobre os ambientes digitais não seja sempre tão inteligível. Claro que, em uma sociedade como a da Rússia, onde as televisões ainda detêm um papel grande como fonte de mídia com agenda política conspícua que afeta o comportamento e as atitudes políticas (PEISAKHIN; ROZENAS, 2018), certamente existe uma interdependência entre as agendas, ou seja, parte da agenda do Youtube Russo (pelo menos no que se refere ao interesse dos internautas) certamente é reflexo direto do agendamento da imprensa tradicional (CUNNINGHAM; CRAIG; SILVER, 2016). Nesse ponto, alguns estudos recentes apontam a existência de uma forte simbiose entre os debates eleitorais televisivos e a repercussão destes no Youtube. Esse núcleo duro por assim dizer, do "efeito debate presidencial", fenômeno estudado até então nas eleições brasileiras de 2014 (MORAES; QUADROS, 2015) e de 2006 e 2010 (MORAES, 2018), Argentinas de 2015 (MORAES, QUADROS, SANTOS, 2017) e dos Estados Unidos em 2016 (MORAES, 2017a) onde se aferiu basicamente que, os debates eleitorais afetam, enquanto variável independe, diretamente o nível de interesse dos internautas no Youtube pelos candidatos à disputa presidencial. Neste ponto, este trabalho segue em continuidade a esta agenda de pesquisa estudando o "efeito debate" nas eleições presidenciais Russas de 2018, onde houveram 4 debates televisivos. 
Em verdade, é possível afirmar que os debates eleitorais proporcionam uma forma de comunicação política muito mais marcante que outros padrões de comunicação, sobretudo por oferecerem aos candidatos formas de se expressarem diretamente em ritmo de confronto com os adversários em dialéticas que geralmente sintetizam os temas da campanha. Neste trabalho piloto aplicou-se uma metodologia baseada no motor de busca reversa do Google Trends para aferir, dentro do cenário das eleições russas de 2016, como os internautas responderam aos debates presidenciais televisionados.

\section{YOUTUBE, POLÍtICA E DEBATES PRESIDENCIAIS NA RÚSSIA}

Os pesquisadores Bernhard Rieder, Adriadna Matamoros-Fernandez e Òscar Coromina (2018) pontuam que o Youtube foi lançado em 2005 e adquirido pelo Google ${ }^{1}$ um ano depois e é hoje o segundo site mais visitado em todo mundo com mais de um bilhão de usuários assistidos centenas de milhares de horas de conteúdo todos os dias. Muitas pesquisas desde então vem se desdobrando em diferentes áreas das ciências sociais e computacionais para aferir os aspectos relacionados à produção, disseminação e participação nesta rede social. Uma das maiores dificuldades comum aos estudos que se debruçam sobre o Youtube é conceitualizar e entender em perspectiva interdisciplinar como os diversos atores sociais orquestram diferentes relações que vão desde usuários finais até anunciantes. Essas relações são concretizadas como um conjunto de interações de grande complexidade que são apregoadas pelos processos que ocorrem toda vez que uma busca é lançada nos motores de pesquisa, que se traduz, por conseguinte na forma de operações algorítmicas e em conjuntos de sinais de dados que representam as diferentes práticas envolvidas, onde não a

1 A história de pelo menos 10 anos do Youtube e do Google pode ser descrita como uma empreitada onde o Google buscou entrar em acordo com as condições de possibilidade de entretenimento, conteúdo e desenvolvimento de talentos de sua base como uma empresa de Tecnologia da informação pautada na automação permanente, na prototipagem rápida e, sobretudo na interação. Como conseqüência destes esforços e contestações em relação aos modelos de mídia tradicionais, particularmente os voltados para negócios. De toda forma, parece nascer da liquidifiques deste esforço um estrato que se plasma na forma de uma nova ecologia do Youtube, que levou ao florescer de ambientes inimagináveis de criatividade e de cultura on-line emergente, de forma concomitante ao turbulento e precário mercado dos criadores de conteúdo dos veículos tradicionais (CUNNINGHAM; CRAIG; SILVER, 2016). 
"busca", mas o "resultado" do que se procura no motor da ferramenta pode ser considerado como a produção de algo que entrelaça as políticas da plataforma e também as culturas quanto ao uso. Diferente de Bernhard Rieder, Adriadna Matamoros-Fernandez e Òscar Coromina (2018), nosso estudo não irá se centrar no algoritmo que determina os resultados apresentados aos usuários, mas tão somente na "cultura de uso", mensurada nos padrões com os quais os internautas demandam interesse. Do ponto de vista empírico cremos que este seja o caminho mais verossímil para cumprir com os padrões de replicação e que menos deixa margem de dúvida sobre a estrutura dos dados.

Quanto ao universo russo o Youtube estabelece um novo ritmo no que diz respeito a compartilhar e vivenciar conhecimento através de vídeos, pois permite que o internauta além de publicar conteúdo também possa assistir aos materiais, comentar e interagir. É dizer nesse sentido que, do ponto de vista político e social, o Youtube pode facilitar a criação de uma prática de compartilhamento democrático de memórias e informações permitindo que cidadãos comuns exponham e compartilhem suas visões, ou seja, um efeito que permite um maior nivelamento entre o mainstream disseminador de informações e o cidadão comum (MARRES; MOATS, 2015; MORAES; QUADROS, 2015; CUNNINGHAM; CRAIG; SILVER, 2016; MAKHORTYKH, 2018). Claro que o Youtube também imita o papel da televisão, legalmente pautando-se na distribuição de conteúdo de transmissão e suavizando os links entre os conteúdos e os comerciais em um ponto onde as ações de direitos autorais fizeram a plataforma programar políticas estritas, tornando o conteúdo original gerado pelo usuário como uma meta de receita crucial. Esse processo de industrialização do Youtube também fica evidente enquanto uma empresa que constrói discursivamente seus negócios como uma plataforma facilitadora (porém neutra) posicionando-se estrategicamente entre os usuários, anunciantes, criadores de conteúdo e reguladores legislativos. Embora a função do mecanismo de pesquisa seja estabelecer a conexão entre usuários e conteúdos é principalmente o conteúdo atrativo que é produzido profissionalmente que dá força ao Youtube. É fato que o Youtube também coopera com os principais produtores de transmissão para preencher seus canais, entretanto, esse tipo de conteúdo já é amplamente disputado com plataformas especializadas neste tipo de streaming, como Netflix e Amazon. Em vista disso os criadores de conteúdos locais fornecem alguns conteúdos específicos para anunciantes e assinantes engajados, 
como um novo nicho estratégico dentro da ampla ecologia de oportunidades do Youtube (LOBATO, 2016; HOU, 2018).

De toda forma, Noortje Marres e David Moats (2015) e Ramon Lobato (2015) argumentam que, por conta da ampla importância contemporânea do Youtube, uma promissora e concisa agenda de pesquisa se prolifera com o intuito de mensurar, as determinantes e os "efeitos" relacionados à dinâmica de conteúdo da plataforma. Existe uma ambiguidade quanto ao objeto empírico. Dentro desta seara algumas pesquisas se preocuparam mais com a observação de "fenômenos baseados na web", enquanto que em outras formas de análise estavam interessadas em aferir os fenômenos exógenos à web, porém, ao que parece, várias características das plataformas online se combinam para tornar essa questão particularmente saliente quanto aos métodos de pesquisa de mídias sociais.

Quanto ao Youtube e seu uso político na Rússia, Frank Weij e Pauwke Berkers (2017) destacam que a plataforma tem um potencial muito diferenciado, com nítidas fronteiras geopolíticas de ativismo em um ambiente onde se fomenta comprometimento e legalidade por parte dos ativistas como uma via de protesto político e também com uma rota de conflito para com valores tradicionais. O entendimento ocorre semelhante ao já vislumbrado no Ocidente, onde os cientistas políticos se referem a espaços como o Youtube como "terceiros espaços", uma extensão em forma de plataforma equivalente ao trabalho e a casa, que oferece um cenário de conversas políticas cotidianas. Mesmo que os vídeos políticos não sejam os mais vistos entre os usuários de Youtube na Rússia, existem evidências de um fluxo significativo de material político que muitas vezes atraem imensa repercussão.

Neste mesmo ângulo Vlad Strukov (2012) denota que entre 2011 e 2012 a política começou a galgar outro ritmo na internet Rússia, desvinculando-se em princípio do fluxo de programas da televisão. Isso não quer dizer que a maior parte do eleitorado russo esteve on-line acompanhando as notícias políticas, mas sim, que a mídia Russa entrou definitivamente na fase pós-difusão com produtos multimídia para plataformas on-line com ampla circulação e impacto sob o discurso político cotidiano. É dizer que pela primeira vez o povo russo foi exposto a um espetáculo político em rede mediado que proporcionou ao eleitorado uma sensação maior de participação. Um exemplo interessante é a repercussão que os debates presidenciais tiveram dentro da plataforma Youtube, principalmente os protagonizados pelos 
candidatos Vladimir Zhirinovsky e Mikhail Prokhorov, um cenário muito semelhante aos talk shows russos, com debates menos intimidantes e que ao mesmo tempo trouxeram alusões de ironia. Não é dizer que o info-entretenimento aqui tenha substituído à discussão política genuína, mas levou-a para o reino popular, o que fora aparentemente uma fórmula positiva para atrair russos desencantados.

É pertinente notar que neste contexto de 2011-2012 os assessores políticos aconselharam Vladimir Putin a se abster da participação nos debates alegando que sua popularidade poderia causar um efeito positivo nas taxas de votação dos demais candidatos. Essa ausência conspícua dos debates por parte de Putin significa a imagem do presidente só é publicizada quando seu desempenho é cuidadosamente orquestrado. Dentro dessa seara o representante da imagem de Putin foi o cineasta Nikita Mikhalkov (conhecido por sua agenda nacionalista, monarquista e leal ao governo) que protagonizou alguns debates contra Irina Prokhorova (STRUKOV, 2012).

A proliferação agressiva de novas mídias na Rússia resulta do surgimento de novos tipos de públicos que não buscam apenas diversão ou que passam a maior parte do tempo comparando experiências políticas online, mas também de públicos aleatórios e sujeitos que se unem para abordar questões sociais específicas. Como resultado os russos tem a sensação de estarem conectados, pelo menos tecnologicamente, com as novas linhas de separação que vem sendo traçadas ao longo da internet e de seus domínios digitais. Os usuários politicamente ativos das novas mídias na Rússia pertencem mais ou menos à geração da época da perestroika, ou seja, eram adolescentes quando Mikhail Gorbachev anunciou a aceleração, portanto, a moda política deste tempo parece ter voltado e é possível que as novas elites russas mantenham os valores que foram adquiridos nos debates do final dos anos 1980 (STRUKOV, 2012; SAUNDERS; STRUKOV, 2017).

No calor do debate político é importante notar que a mídia russa entrou em uma fase pós-transmissão, nesse caso desde a década de 1990 houve intensas batalhas entre os canais de televisão russos. O resultado foi que alguns canais encerraram suas atividades enquanto que outros se transformaram (muitas vezes migrando para uma direção oposta da proposta inicial). A década de 2000 representou um novo nível nessa disputa, um confronto entre a televisão e a internet, sendo que a segunda trouxe consigo uma "lógica libertadora", própria dos recursos gerados pelos usuários da democracia. Claro que obviamente a tecnologia por si só não abriu um 
caminho para uma sociedade mais democrática na Rússia, mais trouxe novos caminhos a serem explorados. Paralelo ao padrão de programação política produzida pelos principais canais de televisão na Rússia tem-se o sabor de um cenário cuidadosamente encenado, severo e um pouco "soviético" frente à vida política. Na outra ponta canais de televisão digital com um novo padrão estético apresentam campanhas publicitárias de destaque com discussões políticas que reforçam a interatividade com o usuário. Nesse caminho o Youtube vem se destacando como a maior fórmula de "sinceridade televisiva russa" da mesma forma que o Twitter $^{2}$ vem oferecendo a sensação de imediatismo quanto à participação no debate político (STRUKOV, 2012; SAUNDERS; STRUKOV, 2017).

Karina Alexanyan e seus colaboradores (2014) realizaram um amplo projeto de estudo sobre o ciberespaço russo empregando múltiplos métodos para estudar as atividades on-line, dentre eles, o mapeamento da estrutura das comunidades, análise do conteúdo das blogsferas, análise de Twitter e também do âmago de diferentes conteúdos de mídia usando abordagens e avaliações automatizadas além de abordagens baseadas no crivo humano como entrevista com blogueiros russos e pesquisa de background. Os autores relataram-se otimistas nos resultados, visto que conseguiram "fotografar" o surgimento de uma esfera pública vibrante em rede, diversificada, que constitui uma sólida alternativa independente à mídia off-line e ao espaço político rigidamente controlado, além disso, foi evidente o crescente uso das plataformas digitais como espaço de mobilização social

2 O Twitter em particular desempenhou um papel proeminente durante as duas eleições russas para a Câmara Legislativa do Parlamento da Federação Russa de dezembro de 2011 e também nas eleições presidenciais de março de 2012, bem como, nos protestos que ocorreram durante esse período. Os russos tuitaram os resultados das eleições nas suas assembleias de votos locais, postaram links para vídeos e fotos documentando fraudes eleitorais, prisões de figuras proeminentes de oposição, como Alexey Navalny e informações vinculadas aos eventos de protestos (futuros e passados). O Twitter foi particularmente importante porque muitos sites proeminentes de oposição foram retirados ou hackeados durante e após as eleições de dezembro de 2011, o que fez do Twitter uma das poucas plataformas que não tiveram serviços suspensos, embora as hashtags opostas ao regime fossem inundadas por spams pró-regime. As evidências empíricas neste contexto indicaram que os usuários pró-governo empregaram uma variedade de estratégias de comunicação para mudar o discurso político e por outro lado marginalizar as vozes tidas como oposição a Putin no Twitter. Em larga medida isso demonstra que as autoridades russas se preocupam em atuar no sentido de enfraquecer os críticos do regime e também em manipular a opinião pública por meio das mídias sociais (não só no Twitter). (SPAISER et al., 2017). 
e na ação cívica. Os autores afirmam que, apesar de vários esforços diretos e indiretos por parte do governo para moldar o ciberespaço de forma a adquirir obrigatoriamente um ambiente amigável e favorável ao sistema político, evidencia-se que a internet russa permanece em geral livre e plural.

\section{DEBATES PRESIDENCIAIS E AUDIÊNCIA VIA YOUTUBE}

Apesar do efeito interessante que existe entre a comunicação tradicional dos debates presidenciais e a resposta que se gera de repercussão e material dentro do Youtube, são escassas as pesquisas que se debruçam em entender essa simbiose entre o mundo off-line (os debates presidenciais) e o mundo on-line (o impacto deste no Youtube). Como base para a atual metodologia que empregamos neste trabalho destacam-se quatro trabalhos anteriores onde os processos foram amadurecidos, conforme descrevemos a seguir.

No primeiro, Thiago Moraes e Doacir Quadros (2015) delinearam um quase-experimento natural a fim de entender o efeito causado pelos debates dentro da plataforma Youtube durante as eleições presidenciais de 2014 no Brasil. Os resultados até então inéditos na literatura, apontaram que os debates afetaram de maneira consistente o interesse dos internautas em relação aos candidatos, além disso, os programas próximos ao pleito eleitoral tinham mais repercussão no Youtube. $37 \%$ das buscas no Youtube pelo candidato Aécio neves e $9 \%$ das buscas pela candidata Dilma Rousseff foram conseqüência direta dos debates.

No segundo trabalho, Thiago Moraes, Doacir Quadros e Romer Santos (2016) aplicaram a mesma metodologia para estudar os debates presidenciais na Argentina em 2015 (os primeiros televisionados desde a redemocratização do país). Os resultados encontraram que os debates próximos ao pleito eleitoral dia $\mathrm{D}$ foram os mais atrativos para os usuários do Youtube, $\mathrm{e}$ que no segundo turno, quase $30 \%$ das buscas efetuadas nos buscadores do Youtube por Mauricio Macri, e mais de $40 \%$ das realizadas pelo candidato Daniel Scioli foram respostas diretas dos debates, o que reforça a interação entre as duas ferramentas.

A posteriori em um terceiro trabalho, a metodologia foi empregada por Thiago Moraes (2017a) que mensurou o efeito que os debates presidenciais entre Hillary Clinton e Donald Trump tiveram no Youtube durante as eleições de 2016. O resultado mostra que os candidatos dependem muito dos debates para ganharem fluxo de interesse no Youtube, visto boa parte das 
buscas no Youtube por ambos os candidatos foram conseqüência direta dos debates. Além disso, apesar de Trump ter vencido a disputa, os debates, pelo menos no Youtube, elevaram (um pouco mais) o interesse dos internautas em relação à candidata mais do que em relação à Trump. Neste trabalho, damos continuidade ao esforço de mensurar o "efeito debate" no universo do Youtube trazendo as eleições Russas como cenário pouco explorado a se averiguar.

Por fim, destaca-se o trabalho de Thiago Moraes (2018) que mensurou com o Google Trends o efeito dos debates presidenciais nas buscas dos internautas durante as eleições de 2006 e 2010 no Brasil. O resultado do estudo sinaliza que (com exceção do $2^{\circ}$ turno de 2010) houve em todos os casos a influência dos debates presidenciais nas buscas dos internautas, além disso, em comparação com os demais partidos atuantes na disputa, o Partido dos Trabalhadores foi o que mais conseguiu visibilidade entre os internautas brasileiros.

\section{ELEIÇÃO RÚSSIA 2018 E INTERNET}

Como indaga Inga Saikkonen (2018), a participação eleitoral tem sido geralmente mais alta nas eleições presidenciais russas do que nas eleições parlamentares, mas ainda assim, verifica-se nos últimos anos uma queda no comparecimento às urnas. Eleições em regimes autoritários tais como a Rússia, tendem a transitar em torno de assuntos predeterminados que raramente representam uma ameaça ao poder do regime governante. Claro que uma baixa participação, mesmo no contexto de uma vitória esmagadora para o regime, pode deslegitimar o resultado eleitoral e sinalizar oposições ocultas dentro de uma população. Por conta disso as autoridades russas procuram invocar um maior interesse público nas eleições trazendo novas caras para o pleito, como a do candidato Pavel Grudinin (Partido Comunista) ou ainda da popular Ksenia Sobchak.

Quanto à ciberesfera política russa os cientistas políticos Tantsura Marina Sergeyevna, Gritsenko Ruslan Artemovich e Prokopchuk Dmitry Dmitrievich (2018) indagam que até 2018 as principais tendências quanto ao uso de tecnologias que formam as preferências eleitorais, parecem bem claras, sendo elas:

(I) A internet hoje está sendo aplicada com sucesso pelos partidos políticos russos que visam aumentar o eleitorado principalmente à custa de públicos mais jovens. 
(II) A internet tem permitido que os partidos e outras estruturas públicas consigam contornar os meios tradicionais de divulgação de informação na Rússia para fazer campanha e mobilizar apoiantes, algo que certamente se plasmou de forma forte na figura política de Navalny.

(III) O conteúdo político no ciberespaço russo geralmente é criado e adaptado aos interesses jovens, bem como às características próprias do espaço da internet.

Na mesma esteira Tantsura Marina Sergeyevna, Gritsenko Ruslan Artemovich e Prokopchuk Dmitry Dmitrievich (2018) ainda pontuam que os políticos profissionais russos, independente da vontade das forças políticas de usar a tecnologia da internet para atingir seus fins, ignorarem esta, bem como as ações decorrentes dela, não é mais um erro nem tampouco uma opção perdoável de qualquer campanha com nível e amplitude de cobertura. Empiricamente as pesquisas indicam que, o maior volume de uso da internet na Rússia para fins políticos se deu nas eleições de 2016, com um salto quantitativamente muito elevado em relação a 2011, o que parece ser uma tendência que irá se manifestar de forma cada vez mais forte nos próximos ciclos eleitorais russos.

\section{METODOLOGIA}

Neste trabalho um quase experimento natural foi delineado utilizando uma metodologia adaptada a partir de estudos anteriores que mensuraram os efeitos que os debates eleitorais tiveram na rede Youtube durante as eleições Brasileiras de 2006, 2010 e 2014 (MORAES; QUADROS, 2015; MORAES, 2018), no pleito presidencial argentino de 2015 (MORAES; QUADROS; SANTOS, 2016) e a também nas eleições Americanas de 2016 (MORAES, 2017a). Conforme definimos no Quadro 1 a seguir, a metodologia proposta neste estudo contém os 3 passos observados nas pesquisas anteriores mas acrescentamos mais um ponto, relativo a um fenômeno externo ao universo on-line, as intenções de voto.

Quadro 1: Passos para o estudo sistematizado da relação entre Debates presidenciais e Youtube

(I) Definir com a ferramenta Google Trends uma freqüência temporal relativa a buscas efetuadas no Youtube (ou executadas no Google que levaram ao Youtube), durante o período eleitoral. Essa deve ser a variável preditora do modelo. 
(II) Com o Google Trends, da mesma forma que no primeiro caso, deve-se estabelecer um recorte temporal relativo às buscas que levaram a vídeos sobre os candidatos na disputa eleitoral durante o período, sendo que, estas devem ser as variáveis dependentes do modelo.

(III) Por fim a construção do modelo de regressão linear deve ser feita considerando como variável dependente as buscas de informações no Youtube sobre os candidatos e como variável independente considera-se a freqüência de buscas pelos debates.

(IV) Construir uma métrica, comparável entre os candidatos, sobre a evolução, ao longo do período eleitoral das intenções de voto com base na compilação de dados de institutos de opinião. Essa deve ser a variável dependente em um modelo que considere primeiro como variável independente a freqüência de buscas no Youtube pelos debates, e em outro modelo, a mesma variável dependente deve ser comparada com as buscas por cada candidato no Youtube (enquanto variável independente).

Fonte: Adaptado de Thiago Moraes (2017a).

Nesse sentido nosso objetivo é por um lado, aperfeiçoar a metodologia acrescentando outros elementos, a fim de consolidar essa "nova agenda de pesquisa" sobre os efeitos dos debates presidenciais em grandes democracias e por outro lado, a investigação almeja desnudar com mais clareza a dinâmica da participação e do interesse político aferido entre os internautas russos, um tema pouco explorado, do ponto de vista empírico, nos últimos anos. O trabalho objetiva de alguma forma assolar a divisão comentada por Noortje Marres e David Moats (2015), comum entre fenômenos na web (e que a extrapola), propondo um eixo de discussão que permita mensurar os efeitos causais dentro do fluxo do Youtube e também, a possível influência desses em fatores externos, aqui plasmado nas intenções de voto, o que permite compreender os "três eixos": (a) empírico científico, (b) performativo e (c) radicalmente empirista.

Esse trabalho se propõe a responder três perguntas:

(I) Somente Putin ou, os demais candidatos "outsiders" também tiveram "espaço" dentre o interesse dos internautas russos?

(II) Os debates eleitorais afetaram de alguma forma o fluxo de interesse dos internautas russos pelos candidatos que correram na disputa eleitoral?

(III) O interesse pelos candidatos na plataforma Youtube, em perspectiva temporal, pode ter exercido algum efeito sobre a distribuição de intenções de votos mensuradas pelas pesquisas de opinião?

Para tanto cinco hipóteses foram delineadas:

(a) Provavelmente Putin tenha sido o mais "notado" nas buscas de interesse, todavia, é possível que os outros candidatos, inclusive os considerados "mais outsiders" na disputa tenham adquirido também grande visibi- 
lidade.

(b) É provável que os debates tenham afetado de forma significativa a busca pelos candidatos na plataforma Youtube, mesmo no caso de Putin, que não participou de nenhum dos debates (mas que foi um dos "assuntos" principais dos mesmos).

(c) Apesar de ser presumível que ocorra um efeito simbiótico entre o debate presidencial e a busca posterior pelo candidato no Youtube é esperável que tal efeito seja concentrado não atingindo todos os candidatos em igual proporção.

(d) Com base no efeito aferido nos demais estudos sobre a proximidade em relação ao dia da eleição e a elevação do interesse pelo debate (MORAES; QUADROS, 2015; MORAES; QUADROS; SANTOS, 2016; MORAES, 2017b; MORAES, 2018), trabalhamos também com uma quarta hipótese onde possivelmente aqui a proximidade com o dia $D$ também se destaque dentro dos eixos de ascensão do interesse por debate.

(e) Apesar de possivelmente haver um efeito em que o debate estimule a visualização no Youtube, provavelmente o acesso à busca de candidatos nesta rede não é um fator decisivo em afetar as intenções de voto.

Os dados foram coletados e compilados com o Google Trends, segmentado como filtro apenas as entradas destinadas ao Youtube (considerando como recorte espacial o território russo e como temporal o período de 1 mês -11/02/2018 até 11/03/2018. As frequências elencadas são do tipo Beta relativas a conjuntos de pesquisas diferentes segmentadas pelo algoritmo do Google Trends como um tópico³.

\section{RESULTADOS}

A seguir para ilustrar a relação entre os debates eleitorais e o interesse manifesto (em perspectiva temporal) em relação aos candidatos à presidência em vídeos do Youtube, plasmou-se no Gráfico 1 e também na estatística descritiva na Tabela 1, a distribuição temporal de buscas efetuadas no Youtube.

3 O algoritmo da ferramenta constrói a métrica de acordo com a relevância e a significância das correlações. 
Gráfico 1: Distribuição de buscas no Youtube

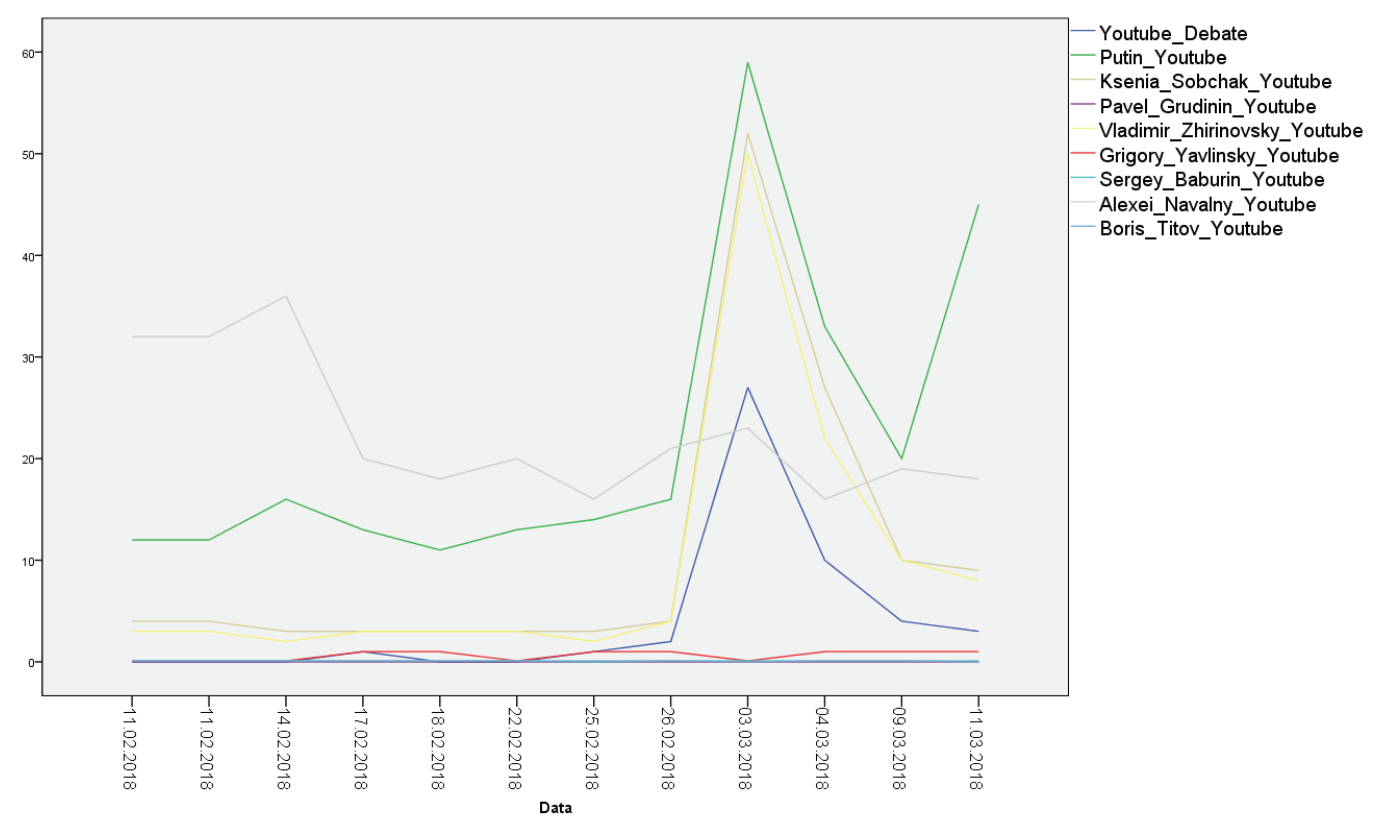

Fonte: $\mathrm{O}$ autor.

Tabela 1: Distribuição de buscas no Youtube

\begin{tabular}{|l|l|l|l|l|l|l|}
\hline & Média & Máximo & Mínimo & Amplitude & Desvio padrão & Soma \\
\hline Debate & 4,00 & 27,00 &, 00 & 27,00 & 7,79 & 48,00 \\
\hline Putin & 22,00 & 59,00 & 11,00 & 48,00 & 15,50 & 264,00 \\
\hline Ksenia Sobchak & 10,42 & 52,00 & 3,00 & 49,00 & 14,79 & 125,00 \\
\hline Pavel Grudinin &, 00 &, 00 &, 00 &, 00 &, 00 &, 00 \\
\hline Vladimir Zhirinovsky & 9,42 & 50,00 & 2,00 & 48,00 & 13,99 & 113,00 \\
\hline Grigory Yavlinsky &, 63 & 1,00 &, 10 &, 90 &, 46 & 7,50 \\
\hline Sergey Baburin &, 09 &, 10 &, 00 &, 10 &, 03 & 1,10 \\
\hline Alexei Navalny & 22,58 & 36,00 & 16,00 & 20,00 & 6,84 & 271,00 \\
\hline Boris Titov &, 08 &, 10 &, 00 &, 10 &, 04 & 1,00 \\
\hline
\end{tabular}

Fonte: $\mathrm{O}$ autor.

Através da ferramenta Google Trends mensurou-se todas as frequências de buscas no Youtube relativas aos candidatos realizadas por internautas sendo elas diretamente por vídeos de candidatos e ou palavras-chaves relacionadas a estes ao longo do tempo.

O primeiro resultado que é interessante notar é que a proximidade com o último debate (perto do dia D) que assim como em estudos anteriores (MORAES; QUADROS, 2015; MORAES; QUADROS; SANTOS, 2016; MORAES, 2017a; MORAES, 2018) elevou o volume de buscas no Youtube por debate 
a um nível maior do que a resposta que fora obtida em relação aos debates anteriores, o que corrobora nossa quarta hipótese. Além disso, é importante mencionar que Putin foi o candidato que na soma obteve maior visibilidade no Youtube, o que valida nossa primeira hipótese.

Destaca-se também que o segundo maior desvio padrão verificado (depois de Putin) e também segundo maior valor Máximo foi referente à freqüência de buscas pela candidata Ksenia Sobchak, a única mulher a participar da disputa. Ksenia Sobchak já dispunha de um sólido capital social, mas vale mencionar que, aparentemente, o último debate presidencial favoreceu muito sua visibilidade no Youtube. É importante sublinhar que, como preconiza Evgenia Olimpieva (2018) Ksenia Sobchak era filha do primeiro prefeito democraticamente eleito de São Petersburgo e além deste legado político ela apresentou um popular reality show, tendo também atuado como jornalista política e como ativista. Alguns canais de comunicação da imprensa na época como o The Economist chegaram a afirmar que apesar de Ksenia Sobchak ser uma "verdadeira liberal”, suas participações nas eleições serviram para de alguma forma dividir a oposição diminuindo o apoio ao de Alexei Navalny o arqui-inimigo de Putin.

É congruente mencionar também que, o terceiro com maior visibilidade nas buscas no Youtube foi Vladimir Zhirinovsky, que, assim como Ksenia Sobchak, parece ter tido sua popularidade no Youtube ampliada em parte como uma resposta ao debate presidencial, levando a um ponto de interesse médio muito próximo ao de Sobchak. Neste diapasão Strobe Talbott (2018) alumia que Vladimir Zhirinovsky se destacou ao longo da vida política como um ultranacionalista que se tornou líder do LDPR (anteriormente conhecido como Partido Liberal Democrático da Rússia). Alguns descrevem Vladimir Zhirinovsky como uma espécie de "showman" da política russa com uma retórica ora nacionalista, ora populista, com um grande enfoque antiocidental e um estilo colérico de apego aos confrontos. Uma das primeiras aparições virais de Vladimir Zhirinovsky na internet se deu em 2012 em resposta a um vídeo eleitoral de 30 segundos em se apresentava um trenó puxado por um burro representando o país, algo que foi extremamente debatido nas mídias sociais recebendo principalmente respostas negativas por parte dos internautas russos.

Já o quarto a obter maior visibilidade foi o advogado Grigory Yavlinsky, economista russo que se tornou conhecido por ser o autor do "programa dos 500 dias", que foi um plano de transição da URSS para uma economia 
de livre-mercado. Yavlinsky antes deste pleito já havia concorrido à presidência em outras duas eleições (respectivamente 1996 e 2000) (CHENOY; KUMAR, 2017), o que sinaliza que, talvez, seu "bom desempenho" dentro da arena de buscas do Youtube se deve ao fato do candidato já deter um capital social oriundo de sua vida política. .

Como não é de se estranhar, Boris Titov e Sergey Baburin tiveram uma freqüência ínfima dentro do interesse dos internautas russos. Margarita Zavadskaya (2018) aponta que de um lado Boris Yurievich Titov, político e empresário russo é conhecido como comissário presidencial dos direitos dos empresários (tendo também liderado o Partido do Crescimento). Já Sergey Nikolayevich Baburin se destacou como um político nacionalista (tendo atuado no Comitê de Direito Civil, Criminal, Arbitral e Processual). Em 2018 Já Sergey Nikolayevich Baburin foi candidato pelo Sindicato de Pessoas da Rússia, sendo que, no passado, ele foi líder do partido político Rodina (União Patriótica Nacional da Pátria).

Por fim vale mencionar um resultado que salta aos olhos - Alexei Navalny conseguiu em média, e na soma total, maior visibilidade $(22,58)$ do que Putin $(22,00)$ nas frequências de interesse do Youtube. Vale destacar que, conforme exposto na Tabela 2, a freqüência de interesse gerada em relação à Navalny parece não ter representado, pelo menos do ponto de vista quantitativo, uma "pedra no sapato" para Putin, visto que não houve correlação entre as buscas (padrão neutro).

Tabela 2: Correlações

\begin{tabular}{|l|l|l|l|l|}
\hline & & Putin & Putin Youtube & $\begin{array}{l}\text { Alexei Navalny } \\
\text { Youtube }\end{array}$ \\
\hline & Correlação de Pearson & 1 &,- 037 &,- 189 \\
\hline Putin & Sig. (2 extremidades) & &, 910 &, 556 \\
\hline & N & 12 & 12 & 12 \\
\hline & Correlação de Pearson &,- 037 & 1 &,- 227 \\
\hline Putin & Sig. (2 extremidades) &, 910 & &, 478 \\
\hline & N & 12 & 12 & 12 \\
\hline & Correlação de Pearson &,- 189 &,- 227 & 1 \\
\hline Alexei Navalny & Sig. (2 extremidades) &, 556 &, 478 & \\
\hline & N & 12 & 12 & 12 \\
\hline
\end{tabular}

Fonte: $\mathrm{O}$ autor.

De toda forma é preciso notar com mais precisão sobre quem foi Alexei 
Navalny nessa disputa e porque ele gerou tanta repercussão no Youtube russo. Segundo Aliaksandr Herasimenka (2018), alguns pontos merecem atenção especial nesta matéria: a) Navalny é um atistiva anti-corrupção e que foi detido por 60 dias em um centro de detenção em 2017 se vendo assim impedido de se inscrever como candidato nas eleições presidenciais para março. b) em resposta, construiu uma organização que emergiu como um sério desafio político interno ao regime do presidente Putin. A equipe de Navalny politizou a maior rede social do país, a VK, inundando a rede de discussões atreladas a campanha de Navalny. c) A campanha passa a usar a plataforma Telegram (criptografada) para comunicação evitando a vigilância digital estatal, possibilitando a interação e o planejamento ostensivo por parte dos ativistas. d) Os ativistas criaram uma rede alternativa de Tv dentro do Youtube, através de cada escritório regional Navalny criou seu próprio canal no Youtube e começou a relatar notícias regionais políticas e sociais. e) Navalny investiu especialmente na divulgação em províncias, pela primeira vez trazendo a política às ruas de muitas comunidades russas. Esses núcleos esparsos dentro dos 11 fusos horários russos criaram centenas de páginas regionais em VK e Telegram, além de enviarem milhares de transmissões políticas ao Youtube, com um conteúdo carregado de mensagens anticorrupção, levando Navalny a decolar ao topo das celebridades da mídia social russa. f) Dessa mobilização resultaram-se protestos generalizados em pelo menos 82 cidades russas contra o governo em 26 de março de 2017, como também outras três ondas menores de protestos que se seguiram. Os protestos foram os que tiveram maior extensão geográfica desde o início dos anos 90 e foi organizado com base na infraestrutura digital rápida do conteúdo político postado no Youtube e nas comunidades em mídias sociais locais que se tornou a base para Navalny concorrer 8 meses mais tarde à presidência.

Na mesma esteira Anastasia Kazun, Kseniia Semykina (2018) indagam que em um extremo Navalny conseguiu espaço em notícias de menções políticas no contexto da ordem pública e da criminalidade, com uma associação provavelmente feita pelos meios de comunicação de massa como resposta às críticas feitas por ele ao sistema legal da Rússia. Ao contrário de Navalny, Putin aparece regularmente nas notícias sobre atividades de negócios e também bem-estar nacional e o nível de preços. É claro que Putin como detentor do poder tem uma vantagem intrínseca na construção das associações com temas contemporâneos da agenda pública, principalmente no 
que tange às questões econômicas como desemprego, inflação ou clima de negócios na Rússia.

A seguir na Tabela 3 utilizou-se o índice de Pearson para aferir se existe correlação entre as buscas efetuadas nos motores de busca do Youtube por temas relacionados aos debates presidenciais e as buscas efetuadas em relação aos candidatos à presidência.

Tabela 3: Correlações entre a busca por debates e candidatos no Youtube

\begin{tabular}{|c|c|c|}
\hline & & Youtube Debate \\
\hline & Correlação de Pearson & $859 * *$ \\
\hline \multirow[t]{3}{*}{ Putin } & Sig. ( 2 extremidades) &, 000 \\
\hline & $\mathrm{N}$ & 12 \\
\hline & Correlação de Pearson & $990 * *$ \\
\hline \multirow[t]{3}{*}{ Ksenia Sobchak } & Sig. ( 2 extremidades) & ,000 \\
\hline & $\mathrm{N}$ & 12 \\
\hline & Correlação de Pearson &.$^{b}$ \\
\hline \multirow[t]{3}{*}{ Pavel Grudinin } & Sig. ( 2 extremidades) & . \\
\hline & $\mathrm{N}$ & 12 \\
\hline & Correlação de Pearson & ,996** \\
\hline \multirow[t]{3}{*}{ Vladimir Zhirinovsky } & Sig. ( 2 extremidades) &, 000 \\
\hline & $\mathrm{N}$ & 12 \\
\hline & Correlação de Pearson &,- 159 \\
\hline \multirow[t]{3}{*}{ Grigory Yavlinsky } & Sig. (2 extremidades) & ,623 \\
\hline & $\mathrm{N}$ & 12 \\
\hline & Correlação de Pearson & ,121 \\
\hline \multirow[t]{3}{*}{ Sergey Baburin } & Sig. (2 extremidades) & ,707 \\
\hline & $\mathrm{N}$ & 12 \\
\hline & Correlação de Pearson &,- 162 \\
\hline \multirow[t]{3}{*}{ Alexei Navalny } & Sig. ( 2 extremidades) & ,615 \\
\hline & $\mathrm{N}$ & 12 \\
\hline & Correlação de Pearson &,$- 659 *$ \\
\hline \multirow[t]{3}{*}{ Boris Titov } & Sig. ( 2 extremidades) & ,020 \\
\hline & $\mathrm{N}$ & 12 \\
\hline & Correlação de Pearson & 1 \\
\hline \multirow[t]{2}{*}{ Youtube } & Sig. ( 2 extremidades) & . \\
\hline & $\mathrm{N}$ & 12 \\
\hline
\end{tabular}

**A correlação é significativa no nível 0,01 (2 extremidades).

*. A correlação é significativa no nível 0,05 (2 extremidades).

b. Não é possível calcular porque pelo menos uma das variáveis é constante.

Fonte: $\mathrm{O}$ autor. 
Ao analisar a Tabela 3 evidencia-se que no Youtube houve correlação entre busca por debates e por quatro candidatos, sendo estes: Ksenia Sobchak, Putin, Boris Titov e Vladimir Zhirinovsky. Não houve correlação nesse sentido entre os demais candidatos e o interesse por debates. A seguir traçamos uma previsão utilizando um modelo ARIMA considerando como variável de saída cada um destes quatro candidatos supracitados e como variável preditora o interesse por debates no Youtube.

Gráfico 2: Previsão de buscas no Youtube por candidatos

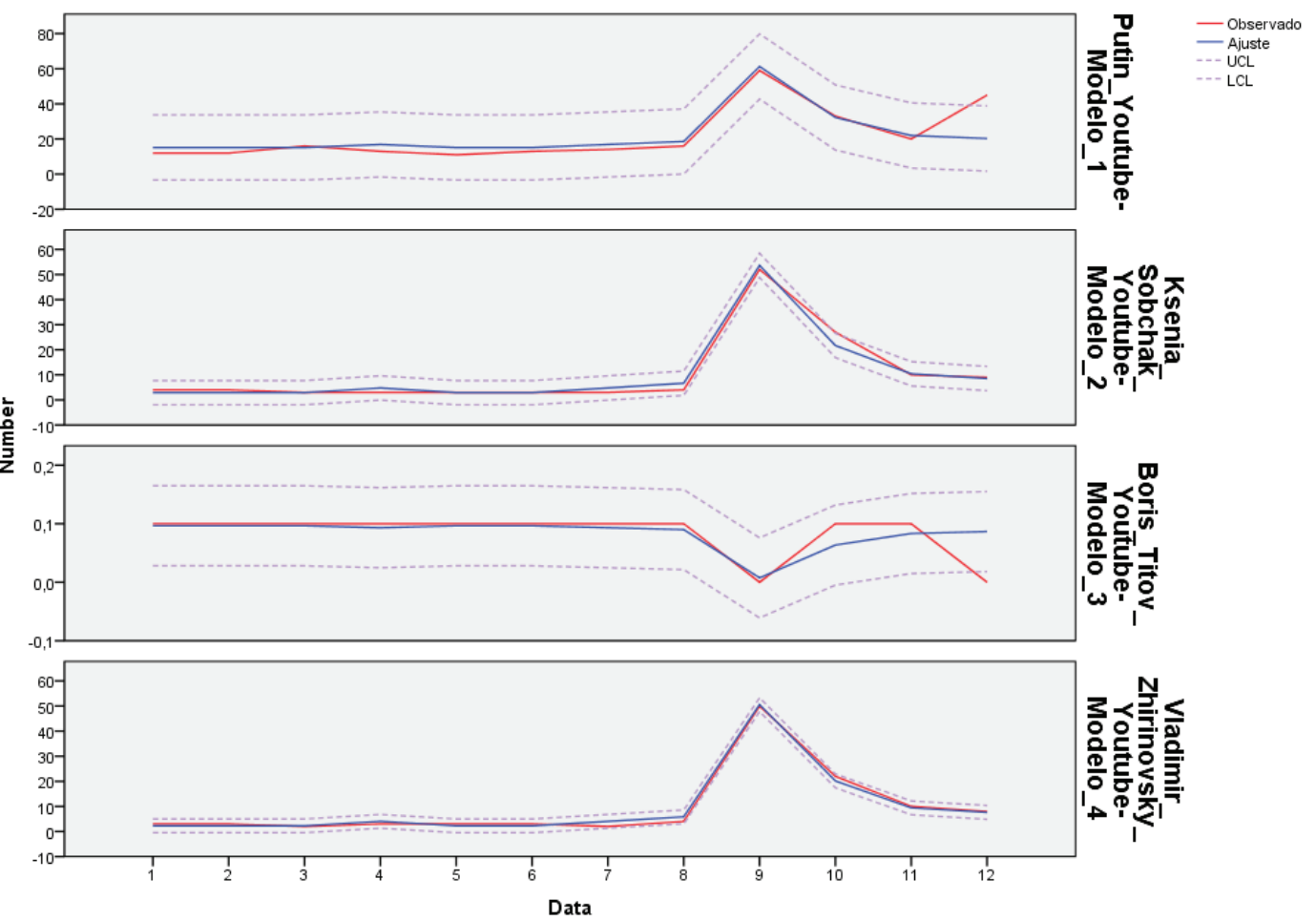

Fonte: $\mathrm{O}$ autor.

Tabela 4: Previsão de buscas no Youtube por candidatos

\begin{tabular}{|c|c|c|c|c|c|c|c|}
\hline $\begin{array}{l}\text { Parâmetroso } \\
\text { Modelo ARIMA }\end{array}$ & Estimativas & SE & t & Sig. & R Quadrado & Anova F & Sig. \\
\hline Putin & 15,168 & 2,727 & 5,303 & 0 & 0,771 & 28,12 &, $000^{\text {b }}$ \\
\hline Ksenia Sobchak & 2,902 & 0,711 & 22,375 & 0 & 0,978 & 500,654 &, $020^{\text {b }}$ \\
\hline Boris Titov & 0,097 & 0,01 & $-2,773$ & 0,02 & 0,378 & 7,691 &, $000^{\text {b }}$ \\
\hline $\begin{array}{c}\text { Vladimir } \\
\text { Zhirinovsky }\end{array}$ & 2,261 & 0,403 & 37,558 & 0 & 0,992 & 1410,627 &, $000^{\text {b }}$ \\
\hline
\end{tabular}

Fonte: $\mathrm{O}$ autor.

É curioso aferir através de nossos modelos preditores que Putin, mesmo 
sem participar dos debates, foi amplamente beneficiado por eles, vide que mais de $77 \%$ das buscas no Youtube feitas em relação a sua pessoa podem ser explicadas pelo interesse dos internautas nos debates presidenciais. Mesmo Boris Titov, talvez o candidato mais "outsider" dentro os descritos no quadro anterior, foi favorecido pelo debate televisivo, visto que mais de $37,8 \%$ das buscas no Youtube pelo nome podem ser explicadas por tal fator. Mas é indubitável que os candidatos que foram mais sensíveis a este efeito foi Ksenia Sobchak e Vladimir Zhirinovsky, visto que em ambos os casos mais de $90 \%$ das buscas no Youtube podem ser interpretados como uma resposta de interesse do internauta ao debate televisivo. Por um lado, nossa segunda hipótese se comprova, visto a significância do efeito, todavia, considerando que o efeito não atingiu os demais candidatos (Pavel Grudinin, Grigory Yavlinsky, Sergey Baburin e Alexei Navalny) considera-se que o efeito aqui foi concentrado (favorecendo uns em revelia de outros) o que corrobora nossa terceira hipótese.

A seguir buscou-se aferir se os debates presidenciais afetaram em alguma proporção as intenções de voto. Na Tabela 5 e no Gráfico 3 a seguir descreve-se a evolução das intenções de voto de acordo com pesquisas de opinião.

Tabela 5: Intenções de voto

\begin{tabular}{|c|c|c|c|c|c|c|}
\hline Fonte & FBK & FBK & FOM & FOM & WCIOM & WCIOM \\
\hline & Média & N total & Média & N total & Média & N total \\
\hline Putin & 56,5 & 2 & 65,4 & 5 & 69,8 & 5 \\
\hline Grudinin & 4,5 & 2 & 5,9 & 5 & 7,3 & 5 \\
\hline Zhirinovsky & 4,0 & 2 & 6,3 & 5 & 5,5 & 5 \\
\hline Yavlinsky &, 0 & 2 &, 7 & 5 & 1,0 & 5 \\
\hline Sobchak &, 5 & 2 & 1,0 & 5 & 1,3 & 5 \\
\hline Titov &, 0 & 2 &, 1 & 5 &, 2 & 5 \\
\hline Baburin &, 0 & 2 &, 1 & 5 &, 5 & 5 \\
\hline Suraykin &, 0 & 2 &, 1 & 5 &, 3 & 5 \\
\hline
\end{tabular}

Fonte: Adaptado a partir de Andrei Semenov (2018). 


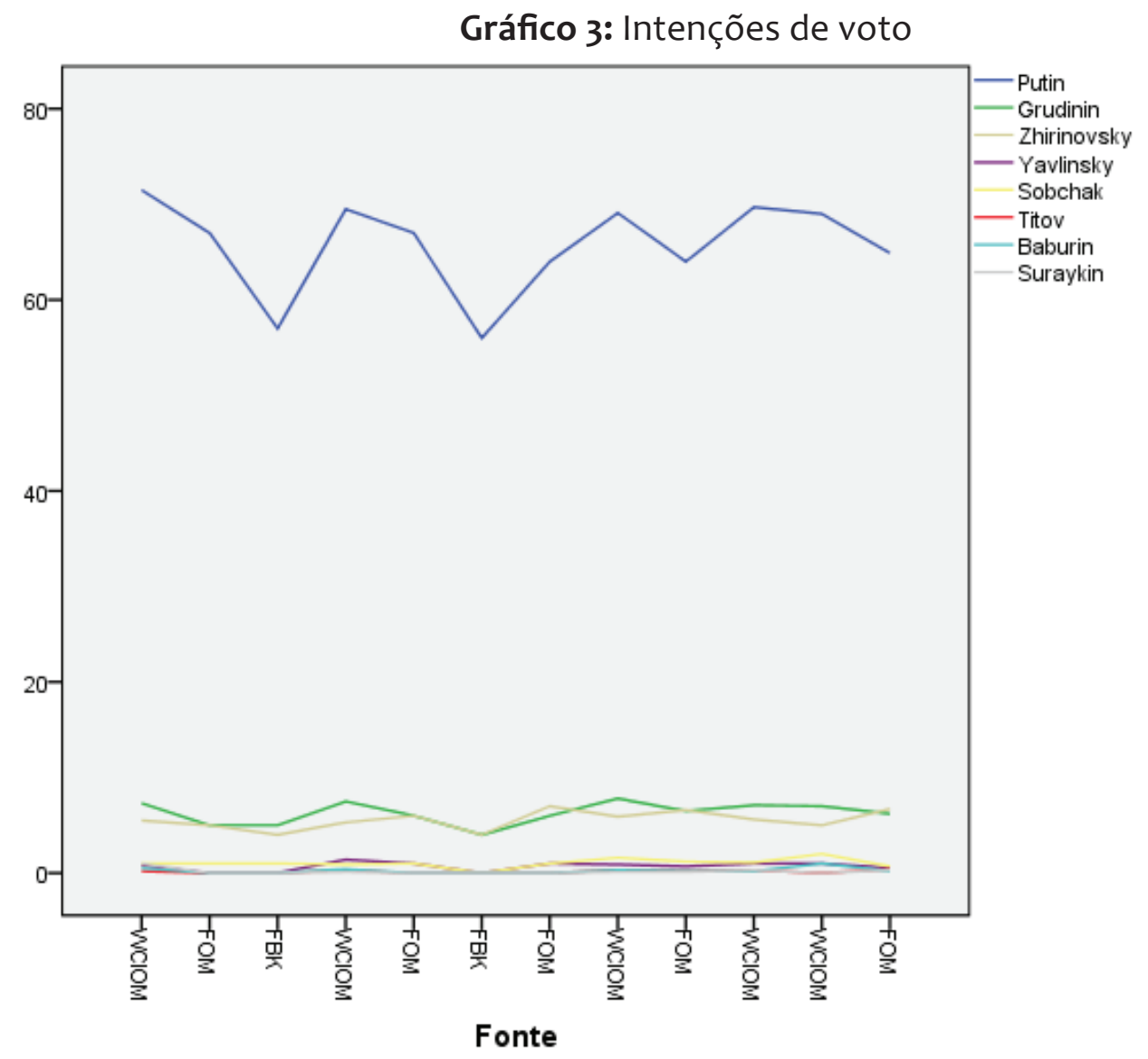

Fonte: Adaptado a partir de Andrei Semenov (2018).

O primeiro resultado que espanta são as intenções de voto de Putin que são mais elevadas do que de todos os demais candidatos juntos. Os candidatos Grudinin e Zhirinovsky foram os candidatos que dividiram $2^{\circ}$ e $3^{\circ}$ posição. Todos os demais, inclusive Sobchack tiveram baixas intenções de votos. $\mathrm{Na}$ Tabela 6 a seguir desenvolve-se um estudo de correlação comparando as intenções de votos com as buscas pelos candidatos no Youtube, que consideramos aqui em parte como conseqüência da aparição dos mesmos nos debates presidenciais televisivos.

Tabela 6: Intenções de votos e buscas no Youtube.

\begin{tabular}{|l|c|c|c|c|c|c|c|c|}
\hline & Putin & $\begin{array}{c}\text { Grudi- } \\
\text { nin }\end{array}$ & $\begin{array}{c}\text { Zhiri- } \\
\text { novsky }\end{array}$ & $\begin{array}{c}\text { Yavlin- } \\
\text { sky }\end{array}$ & $\begin{array}{c}\text { Sob- } \\
\text { chak }\end{array}$ & Titov & $\begin{array}{c}\text { Babu- } \\
\text { rin }\end{array}$ & $\begin{array}{c}\text { Suray- } \\
\text { kin }\end{array}$ \\
\hline & $-0,037$ & 0,152 & 0,483 & 0,03 & 0,072 & 0,502 & 0,033 & 0,046 \\
\hline Putin & 0,91 & 0,638 & 0,112 & 0,925 & 0,824 & 0,096 & 0,919 & 0,887 \\
\hline & 12 & 12 & 12 & 12 & 12 & 12 & 12 & 12 \\
\hline & 0,049 & 0,191 & 0,352 & 0,109 & 0,185 & 0,284 & 0,056 & 0,016 \\
\hline
\end{tabular}


CADERNOS DE COMUNICAÇÃO

UNIVERSIDADE FEDERAL DE SANTA MARIA

\begin{tabular}{|l|c|c|c|c|c|c|c|c|}
\hline $\begin{array}{l}\text { Ksenia } \\
\text { Sobchak }\end{array}$ & 0,88 & 0,552 & 0,262 & 0,736 & 0,566 & 0,372 & 0,863 & 0,96 \\
\hline & 12 & 12 & 12 & 12 & 12 & 12 & 12 & 12 \\
\hline &. $\mathrm{b}$ &. $\mathrm{b}$ &. $\mathrm{b}$ &. $\mathrm{b}$ &. $\mathrm{b}$ &. $\mathrm{b}$ &. $\mathrm{b}$ &. $\mathrm{b}$ \\
\hline $\begin{array}{l}\text { Pavel } \\
\text { Grudinin }\end{array}$ & 12 & 12 & 12 & 12 & 12 & 12 & 12 & 12 \\
\hline & 0,036 & 0,188 & 0,353 & 0,11 & 0,194 & 0,267 & 0,075 & $-0,007$ \\
\hline & 0,912 & 0,559 & 0,26 & 0,734 & 0,546 & 0,402 & 0,817 & 0,982 \\
\hline $\begin{array}{l}\text { Vladimir } \\
\text { Zhirinovsky }\end{array}$ & 12 & 12 & 12 & 12 & 12 & 12 & 12 & 12 \\
\hline & 0,471 & 0,552 & 0,483 &, $749^{* *}$ & 0,374 & 0,338 & 0,272 & $-0,197$ \\
\hline & 0,122 & 0,063 & 0,112 & 0,005 & 0,232 & 0,282 & 0,392 & 0,539 \\
\hline $\begin{array}{l}\text { Grigory } \\
\text { Yavlinsky }\end{array}$ & 12 & 12 & 12 & 12 & 12 & 12 & 12 & 12 \\
\hline & 0,11 & 0,077 & $-0,471$ & $-0,205$ & 0,028 & 0,292 & 0,251 & 0,176 \\
\hline & 0,733 & 0,812 & 0,122 & 0,522 & 0,931 & 0,358 & 0,432 & 0,585 \\
\hline $\begin{array}{l}\text { Sergey } \\
\text { Baburine }\end{array}$ & 12 & 12 & 12 & 12 & 12 & 12 & 12 & 12 \\
\hline & $-0,189$ & $-0,272$ & $-0,509$ &,$- 601 *$ & $-0,026$ & $-0,256$ & $-0,109$ & 0,269 \\
\hline & 0,556 & 0,392 & 0,091 & 0,039 & 0,937 & 0,422 & 0,735 & 0,398 \\
\hline $\begin{array}{l}\text { Alexei } \\
\text { Navalny }\end{array}$ & 12 & 12 & 12 & 12 & 12 & 12 & 12 & 12 \\
\hline & 0,121 & $-0,027$ & $-0,53$ & 0,073 & 0,091 & $-0,473$ & 0,055 & $-0,065$ \\
\hline & 0,708 & 0,934 & 0,076 & 0,822 & 0,778 & 0,121 & 0,864 & 0,84 \\
\hline Boris Titov & 12 & 12 & 12 & 12 & 12 & 12 & 12 \\
\hline & & & & & & & \\
\hline
\end{tabular}

**. A correlação é significativa no nível 0,01 (2 extremidades).

*. A correlação é significativa no nível 0,05 (2 extremidades).

Fonte: $\mathrm{O}$ autor.

O único caso em que houve correlação positiva entre as intenções de votos e as buscas no Youtube foi o de Grigory Yavlinsky. A seguir na regressão linear foi considerada como variável preditora as buscas por Grigory Yavlinsky no Youtube e como variável de saída a evolução das intenções de voto em relação a ele durante o pleito de 2018.

Tabela 7: Resumo do modelo

\begin{tabular}{|c|c|c|c|c|}
\hline Modelo & $\mathrm{R}$ & R quadrado & R quadrado ajustado & Erro padrão da estimativa \\
\hline 1 &, $749^{\mathrm{a}}$ &, 561 &, 517 &, 3221 \\
\hline
\end{tabular}


a. Preditores: (Constante), Grigory Yavlinsky Youtube

b. Variável dependente: Yavlinsky

ANOVA $^{a}$

\begin{tabular}{|c|c|c|c|c|c|c|}
\hline Modelo & & $\begin{array}{c}\text { Soma dos } \\
\text { Quadrados }\end{array}$ & $\mathrm{df}$ & Quadrado Médio & $\mathrm{F}$ & Sig. \\
\hline & Regressão & 1,327 & 1 & 1,327 & 12,794 & ,005 $^{\mathrm{b}}$ \\
\hline 1 & Resíduos & 1,037 & 10 &, 104 & & \\
\hline & Total & 2,365 & 11 & & & \\
\hline
\end{tabular}

a. Variável dependente: Yavlinsky

b. Preditores: (Constante), Grigory Yavlinsky Youtube

Coeficientes $^{\mathrm{a}}$

\begin{tabular}{|c|c|c|c|c|c|c|}
\hline Modelo & & $\begin{array}{c}\text { Coeficientes não } \\
\text { padronizados }\end{array}$ & $\begin{array}{c}\text { Coeficientes não } \\
\text { padronizados }\end{array}$ & $\begin{array}{c}\text { Coeficientes } \\
\text { padroniza- } \\
\text { dos } \\
\end{array}$ & $\mathrm{t}$ & Sig. \\
\hline & & $B$ & Modelo padrão & Beta & & \\
\hline & (Constante) & ,229 & ,161 & & 1,426 & ,184 \\
\hline 1 & $\begin{array}{l}\text { Grigory } \\
\text { Yavlinsky } \\
\text { Youtube }\end{array}$ & ,750 & 210 & ,749 & 3,577 & ,005 \\
\hline
\end{tabular}

a. Variável dependente: Yavlinsky.

Fonte: $\mathrm{O}$ autor.

Visualiza-se que 51,7\% da evolução das intenções de voto em Grigory Yavlinsky podem se relacionar ao interesse do internauta russo por Grigory Yavlinsky nos motores de busca do Youtube. Claro que o resultado pode parecer modesto, considerando que não encontramos, no caso das intenções de voto, um link direto (em relação aos demais candidatos) em relação às buscas no Youtube. Nesse sentido, nossa quinta hipótese está parcialmente corroborada, pois de um lado, evidencia-se que as intenções de voto em Grigory Yavlinsky de fato, podem ter sido significativamente afetadas pelo padrão de buscas no Youtube, contudo, não existe evidência de que os demais candidatos tenham sido afetados por tal efeito.

Porém de toda forma, os demais resultados que aqui apresentamos indica que existe uma simbiose forte entre os programas televisivos e a repercussão dos participantes (e também dos não participantes como no caso de Putin) na rede Youtube. Para os candidatos que investem diretamente na construção da imagem, esse efeito tende a ser muito relevante, considerando que pode favorecer tanto os candidatos que já são mais populares (e que, por conseguinte tem maior enquadramento nos meios de comuni- 
cação de massa) e também pode favorecer os candidatos mais "outsiders" oferecendo um eixo irrestrito de visibilidade, algo que pode tornar mais democrático o padrão de distribuição de informações sobre os diversos candidatos na sociedade russa.

Endossamos aqui a opinião de Tantsura Marina Sergeyevna, Gritsenko Ruslan Artemovich, Prokopchuk Dmitry Dmitrievich (2018) que destacam que certamente o uso da tecnologia virtual em campanhas eleitorais russas irá se expandir a fim de criar novas preferências eleitorais. A intensidade da expansão do conteúdo (e também da melhoria da qualidade) pode depender de quão bem os atores políticos estão engajados em converter seus apoiantes on-line a votarem neles no mundo real, ou, se os partidos conseguiram obter para sua base de filiados todos aqueles que o apoiam no mundo on-line e se esse irá conseguir usar o pode de mobilização da rede para suas ações (manifestações, ações).

\section{CONSIDERAÇÕES FINAIS}

A desigualdade na Rússia quanto à inserção nos meios de comunicação tradicionais é extremamente ampla, segregando claramente os que estão no poder e os que se figuram como em oposição. Fica claro que, no caso da televisão, o estabelecimento de oportunidades para os outsiders parece ser exacerbadamente dificultoso pela limitada liberdade de imprensa. A evidência empírica permite concluir que Vladimir Putin recebeu mais atenção da imprensa do que seu rival político Alexey Navalny e também do que aos demais candidatos. Nesse diapasão considerando que atualmente a televisão é a principal fonte de informação na população russa (86\%) tal cobertura parece dificultar a vida de candidatos que arqueiam suas candidaturas pela internet.

Seguindo o sugerido por Kazun e Semykina (2018), nosso trabalho buscou aferir em que medida, a internet pode ser uma via (aqui representada pelo Youtube) para contrabalancear o efeito de hegemonia dos meios de comunicação tradicionais. Em princípio nossos resultados são otimistas ao sinalizar que de fato, assim como afirmam Tantsura Marina Sergeyevna, Gritsenko Ruslan Artemovich, Prokopchuk Dmitry Dmitrievich (2018), existe sim um frutífero ciber universo político russo, que se plasma não só na ampla quantidade de material que é divulgado pelas plataformas de mídias sociais, mas, como conseguimos mensurar, pela demanda por tal material mensurada nas frequências de buscas do Youtube. Além disso, os resulta- 
dos em alguma proporção permitem que o argumento de Tantsura Marina Sergeyevna, Gritsenko Ruslan Artemovich, Prokopchuk Dmitry Dmitrievich (2018) de que a internet pode ser na Rússia uma via para se transpor a ótica dos meios de comunicação tradicionais se corrobore.

Por um lado, o resultado mostra que, mesmo no universo da internet, Putin foi, supremamente, o candidato aos quais os internautas russos mais buscaram informações sobre, visto que Ksenia Sobchak, a candidata com mais buscas no Youtube depois de Putin, obteve menos da $1 / 2$ do volume de buscas efetuadas pelos usuários russos em comparação as buscas feitas em nome de Putin. É interessante pensar também que, mesmo Putin não participando dos debates, cada um dos três eventos afetou positivamente a ascensão do volume de buscas pelo mesmo no Youtube, sendo que mais de $77 \%$ das buscas efetuadas em seu nome podem ser explicadas por tal fator. Os candidatos que mais ganharam visibilidade no Youtube como resposta aos debates eleitorais na Televisão foram Ksenia Sobchak e Vladimir Zhirinovsky, sendo que os debates enquanto variáveis independentes respondem respectivamente por $97 \%$ das buscas da primeira e $99 \%$ do segundo.

Como sentido negativo, apesar da multiplicidade da ciberesfera russa, os resultados mostram que apesar dos debates eleitorais televisivos impulsionarem amplamente o interesse por alguns candidatos no Youtube, não existe evidência de que tais buscas afetam as intenções de voto, com exceção de Grigory Yavlinsky que parece ter se beneficiado do efeito. Quanto à proximidade com o dia $\mathrm{D}$, é pertinente notar que de fato o último programa teve maior efeito, porém, mais interessante é ainda perceber que Putin teve uma grande ascensão no Youtube neste período, em revelia de seus adversários. Mesmo não sendo o foco deste trabalho, é meritório citar que, apesar de Navalny ter se destacado como o grande "arqui-inimigo" de Putin, nossos dados mostram que, pelo menos no universo do Youtube, apesar da crescente influência de Navalny, ele não parece ter feito declinar o interesse dos internautas por Putin, não representando assim obstáculo significativo.

\section{REFERÊNCIAS}

ALEXANYAN, Karina et al. Explorando o Ciberespaço Russo: Ação Coletiva Digitalmente Mediada e a Esfera Pública Interconectada. Revista de Direito, Estado e Telecomunicações, v. 6, n. 1, p.21-44, 2014.

CHENOY, Anuradha M.; KUMAR, Rajan. Economic Transition and State Capitalism. In: Re-emerging Russia. Palgrave Macmillan, Singapore, p. 153-187, 2017.

CUNNINGHAM, Stuart; CRAIG, David; SILVER, Jon. Youtube, multichannel networks and 
CADERNOS DE COMUNICAÇÃO

UNIVERSIDADE FEDERAL DE SANTA MARIA

the accelerated evolution of the new screen ecology. Convergence, v. 22, n. 4, p. 376-391, 2016.

HERASIMENKA, Aliaksandr. La mort de la democràcia. Capçalera: revista del Col • legi de Periodistes de Catalunya, V.1, n. 178, p. 74-79, 2018.

$\mathrm{HOU}$, Mingyi. Social media celebrity and the institutionalization of Youtube. Convergence, v. 24, n.1, p.1-20, 2018.

KAZUN, Anastasia; SEMYKINA, Kseniia. Presidential Elections 2018: The Struggle of Putin and Navalny for a Media Agenda. National Research University Higher School of Economics, 2018.

LOBATO, Ramon. The cultural logic of digital intermediaries: Youtube multichannel networks. Convergence, v. 22, n. 4, p. 348-360, 2016.

MAKHORTYKH, Mykola. Remediating the past: Youtube and Second World War memory in Ukraine and Russia. Memory Studies, v.10, n.4, p. 1-16, 2017.

MARRES, Noortje; MOATS, David. Mapping controversies with social media: The case for symmetry. Social Media+ Society, v. 1, n. 2, p. 1-17, 2015.

MORAES, T. P. B. de; QUADROS, D.G. de. Dos holofotes para o Youtube: debates e eleição presidencial de 2014. In: Congresso Internacional de Comunicação Política e Estratégias de Campanha, 5., 2016, Buenos Aires: Asociación Lationoamericana de Investigadores En Campañas Electorales, 2016. p. 1 - 13. Disponível em: . Acesso em: 13 ago. 2016.

MORAES, Thiago Perez Bernardes. Os debates presidenciais no Brasil e as buscas no Google (2006-2010). Revista de Ciências Sociais: RCS, v. 49, n. 2, p. 501-536, 2018.

MORAES, Thiago Perez Bernardes de; QUADROS, Doacir Gonçalves de; SANTOS, Romer Mottinha. O peso do espetáculo: debates, internet e eleições presidenciais argentinas (2015). In: Congresso Latino-americano de Ciência Política, 9., 2017, Montevideo. Trabajos presentados. Montevideo: Asociación Latinoamericana de Ciencia Política (ALACIP), 2017. p. 1 - 22. Disponível em: <http://www.congresoalacip2017.org/arquivo/downloadpublic2?q=YToyOntzOjY6InBhcmFtcyl7czozNToiYToxOntzOjEwOiJJRF9BUIFVSVZPIjtzOjQ6IjlzMTYiO30iO3M6MToiaCl7czozMjoiY2E2NzViNzkwYmMoZDcyYTMzMWNjZDRkYjdiMmY5N2YiO30\%3D>. Acesso em: 14 fev. 2018.

MORAES, Thiago Perez Bernardes. Confronto de gigantes: os debates presidenciais e as buscas dos internautas estadunidenses em 2016. Revista Cesumar-Ciências Humanas e Sociais Aplicadas, v. 22, n. 1, p. 39-60, 2017 a.

MORAES, Thiago Perez Bernardes. Confronto de gigantes: os debates presidenciais e as buscas dos internautas estadunidenses em 2016. Revista Cesumar-Ciências Humanas e Sociais Aplicadas, v. 22, n. 1, p. 39-60, 2017b.

OLIMPIEVA, Evgenia. Who Is Ms. Sobchak? Russian Analytical Digest, v. 9, n. 215, p.2-4, 2018.

PEISAKHIN, Leonid; ROZENAS, Arturas. Electoral effects of biased media: Russian television in Ukraine. American Journal of Political Science, v. 62, n. 3, p. 535-550, 2018.

RIEDER, Bernhard; MATAMOROS-FERNÁNDEZ, Ariadna; COROMINA, Òscar. From ranking 
algorithms to 'ranking cultures' Investigating the modulation of visibility in Youtube search results. Convergence, v. 24, n. 1, p. 50-68, 2018.

SAIKKONEN, Inga. Voter Turnout and Electoral Mobilization in Russian Federal Elections. Russian Analytical Digest, v. 9, n. 215, p.12-15, 2018.

SAUNDERS, Robert A.; STRUKOV, Vlad. The Popular Geopolitics Feedback Loop: Thinking Beyond the 'Russia against the West'Paradigm. Europe-Asia Studies, v. 69, n. 2, p. 303324, 2017.

SEMENOVE, Andrei. The Fight for Turnout: Growing Personalism in the Russian Presidential Elections of 2018. RUSSIAN ANALYTICAL DIGEST, v. 26, n. 217, p.5-8, 2018.

SERGEYEVNA, Tantsura Marina; ARTEMOVICH, Gritsenko Ruslan; DMITRIEVICH, Prokopchuk Dmitry. Comparative analysis of internet technologies in russian political campaign during the 2011 and 2016 elections. Society, Moscou, v. 1, n. 1, p.9-14, jan. 2018. Disponível em: < http://dx.doi.org/10.24158/pep.2018.1.1>. Acesso em: 02 abr. 2018.

SPAISER, Viktoria et al. Communication power struggles on social media: A case study of the 2011-12 Russian protests. Journal of Information Technology \& Politics, v. 14, n. 2, p. 132-153, 2017.

STRUKOV, Vlad. Russian 2011-12: Elections and Digital Media. Digital Icons: Studies in Russian, Eurasian and Central European New Media, v. 12, n.1, p.111-123, 2012.

TALBOTT, Strobe. Clinton and Yeltsin. Diplomatic History, v. 42, n. 4, p. 568-571, 2018.

WEIJ, Frank; BERKERS, Pauwke. The politics of musical activism: Western Youtube reception of Pussy Riot's punk performances. Convergence: The International Journal of Research into New Media Technologies, v.23, n.4, p. 1-20, 2017.

ZAVADSKAYA, Margarita. The Fight for Turnout: Growing Personalism in the Russian Presidential Elections of 2018. Russian Analytical Digest, v. 26, n. 217, p.2-5, 2018. 


\section{Thiago Perez Bernardes de Moraes}

Pós-doutorando do Dipartimento di Giurisprudenza da Università degli Studi di Messina. Doutor em Psicologia Social pela Universidad Argentina John Fitzgerald Kennedy. Professor do Centro Universitário Campos de Andrade.

E-mail: thiagomoraessp@hotmail.com 